This article was downloaded by: [The University of Manchester Library]

On: 28 February 2014, At: 06:48

Publisher: Routledge

Informa Ltd Registered in England and Wales Registered Number: 1072954 Registered

office: Mortimer House, 37-41 Mortimer Street, London W1T 3JH, UK

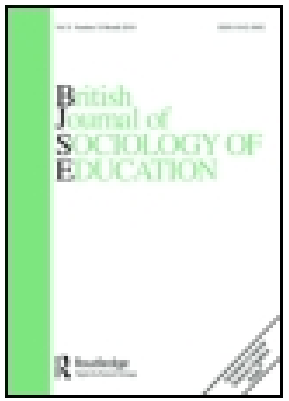

\title{
British Journal of Sociology of Education
}

Publication details, including instructions for authors and subscription information:

http://www.tandfonline.com/loi/cbse20

\section{Between returns and respectability: parental attitudes towards girls' education in rural Punjab, Pakistan}

\author{
Navtej Purewal ${ }^{\mathrm{a}}$ \& Naimatullah Hashmi ${ }^{\mathrm{b}}$ \\ a School of Social Sciences, University of Manchester, Manchester, \\ UK \\ b Department of Statistics, Government College Rawalpindi, \\ Rawalpindi, Pakistan \\ Published online: 26 Feb 2014.
}

To cite this article: Navtej Purewal \& Naimatullah Hashmi (2014): Between returns and respectability: parental attitudes towards girls' education in rural Punjab, Pakistan, British Journal of Sociology of Education, DOI: 10.1080/01425692.2014.883274

To link to this article: http://dx.doi.org/10.1080/01425692.2014.883274

\section{PLEASE SCROLL DOWN FOR ARTICLE}

Taylor \& Francis makes every effort to ensure the accuracy of all the information (the "Content") contained in the publications on our platform. However, Taylor \& Francis, our agents, and our licensors make no representations or warranties whatsoever as to the accuracy, completeness, or suitability for any purpose of the Content. Any opinions and views expressed in this publication are the opinions and views of the authors, and are not the views of or endorsed by Taylor \& Francis. The accuracy of the Content should not be relied upon and should be independently verified with primary sources of information. Taylor and Francis shall not be liable for any losses, actions, claims, proceedings, demands, costs, expenses, damages, and other liabilities whatsoever or howsoever caused arising directly or indirectly in connection with, in relation to or arising out of the use of the Content.

This article may be used for research, teaching, and private study purposes. Any substantial or systematic reproduction, redistribution, reselling, loan, sub-licensing, systematic supply, or distribution in any form to anyone is expressly forbidden. Terms \& 
Conditions of access and use can be found at http://www.tandfonline.com/page/termsand-conditions 


\section{Between returns and respectability: parental attitudes towards girls' education in rural Punjab, Pakistan}

Navtej Purewal ${ }^{\mathrm{a} *}$ and Naimatullah Hashmi ${ }^{\mathrm{b}}$

${ }^{a}$ School of Social Sciences, University of Manchester, Manchester, UK;

${ }^{b}$ Department of Statistics, Government College Rawalpindi, Rawalpindi, Pakistan

(Received 18 July 2012; final version received 2 January 2014)

This article focuses upon perceptions of girls' education in the family context within which decisions around children's education and opportunities are made. The article presents a framework showing how parental attitudes to girls' education are shaped by an objective logic framed by the notion of returns, relating to potential benefits of daughters' education, and respectability, relating to girls' modesty and threats that education may present to normative expectations for girls. Drawing upon data collected in 2011 in rural areas of the districts of Faisalabad (Jaranwala town) and Chiniot (Tehsil Chiniot) in the province of Punjab, the study highlights how assumptions around the liberating effects of education implicit in global education programmes fail to take into account cultural values around gender norms that are central to informing parental attitudes towards their daughters' prospects for education.

Keywords: education; gender; girls' schooling; Pakistan; parental attitudes; Punjab

\section{Introduction}

The 2012 shooting of Malala Yousafzai, then a 14-year-old schoolgirl and campaigner for the rights of girls to attend school in the SWAT Valley of Pakistan in Khyber Pakhtunkhwa, highlighted the extremity of the struggle for girls in Pakistan to have equal access to attend school. Malala's BBC blog highlighted the contestation between girls' education as a basic right and as a transgressive act against religious and cultural conservatism. This article aims to contextualise attitudes and choices made by parents around sending girls to school within this contested terrain of culture and gender norms.

Girls' education continues to lag behind boys' education in most developing countries, with estimates of 93 million children out of school and approximately $80 \%$ of these children living in South Asia or sub-Saharan

*Corresponding author. Email: tej.purewal@manchester.ac.uk 
Africa (DFID 2005; UNICEF 2006). Further to this, female schooling participation in developing countries is still found to be significantly lower than that of their male counterparts in most developing countries, with Pakistan having the lowest gender-specific Education Development Index (0.684) in the South Asian region (Table 1) and being second to last in the World Economic Forum's Gender Gap Index (2013), only behind Yemen.

Pakistan's position within this global context of gender inequalities in education reflects dimensions of both infrastructural inadequacies to provide sufficient education to girls as well as societal values that place less weight on girls' schooling compared with boys' schooling. Attitudes towards girls' schooling are directly associated with cultural values that act as a deterrent to the encouragement of gender-equitable access to education (Hamid 1993). Rather than being viewed as an empowering choice by many parents, girls' education represents a broader index of cultural values, considerations of economic returns, notions of family integrity and gender ideals that, as we will explore, can often lead to ambiguity around the importance of girls being educated, and even an unfavourable attitude towards girls' education. Access to educational opportunities is therefore not only shaped by provision and infrastructure but also by the family context and environment within which decisions and aspirations around children's education are formed. Son preference impacts directly upon daughter discrimination as parents view their household resources as being both finite and structurally skewed towards their sons as inheritors and thus investments for the future of the family (Purewal 2010). Hence, parents do not necessarily see education as a human right but as a discretionary power which they can exert with regards to whether or not to send their daughters to school (Qureshi 2004).

The agency and voice of girls and women is implicit in struggles around the right to education. Women's and girls' voice says much about how systematic discrimination and exclusion from educational opportunity is exercised. Attempts to uncover a strategy for studying gender and culture from the perspective of the 'Third World Woman' as a subject - not an object - of scholarship have framed postcolonial feminism's attention to voice (Minh-ha 1989; Mohanty 1991; Suleri 1992). The identification of a Third World girls' voice in the experiences of and struggles for the rights to education are an overlooked dimension to our understandings of education

Table 1. Education Development Index of South/East Asian countries: overall and gender-wise.

\begin{tabular}{cccccccc}
\hline & India & Bangladesh & Nepal & Indonesia & Philippines & Maldives & Pakistan \\
\hline EDI & 0.797 & 0.759 & 0.734 & 0.935 & 0.839 & 0.910 & 0.640 \\
GEI & 0.811 & 0.976 & 0.810 & 0.959 & 0.955 & 0.952 & 0.684 \\
\hline
\end{tabular}

Note: EDI, Education for All (EFA) Development Index; GEI, Gender-specific EFA Index. Source: Asian Development Bank (2008, 82). 
in South Asia. While public discourse is increasingly being influenced by the global agendas on girls' rights to education, there is also a certain amount of cynicism associated with how universal notions of gender and rights are to be applied to and implemented in Pakistan in relation to, for instance, the Hodood Ordinance, and increasing levels of vulnerability and gendered violence. Poor conditions of government schools, non-availability of schools in local vicinities for rural populations, and the imperatives which household poverty impose on children to work, including girls, also present impediments on female education (SDPI 2008).

\section{Girls' education in rural Pakistan}

Trends reflecting girls' education transcend economic, social and cultural dynamics. Women absorb many of the impacts of economic deprivation (UNFPA 2009), and gender disparities in terms of participation in education in countries with low Human Development Index figures highlight the connections between poverty, gender and social development (Table 2). Girls in rural areas, in particular, are found to have less access to schooling opportunities than their male counterparts (Song, Appleton, and Knight 2006) and are at a further disadvantage to girls in urban areas. This highlights a pattern of relative urban privilege and rural disadvantage in relation to gender patterns of social development. In Pakistan, the literacy rate among rural females of age ' 10 and above' is $35 \%$, whereas it is $67 \%$ among their urban counterparts (Social Indicators of Pakistan 2011). The education gender gap in urban areas has, according to the SDPI (2008, ix), become 'almost nonexistent', while they are further widening in rural education. The National Education Policy of Pakistan (National Population Policy 2010) acknowledged rural-urban and gender disparities in access to education and addressed these disparities through targeted schemes and heightened

Table 2. Human Development Index, public expenditure on education and literacy rates of countries in South and West Asia.

\begin{tabular}{lccccc}
\hline Country & $\begin{array}{c}\text { Human } \\
\text { Development } \\
\text { Index ranking }\end{array}$ & $\begin{array}{c}\text { NER } \\
\text { boys }\end{array}$ & $\begin{array}{c}\text { NER } \\
\text { girls }\end{array}$ & $\begin{array}{c}\text { Public expenditure } \\
\text { on education (as \% } \\
\text { of GNP) }\end{array}$ & $\begin{array}{c}\text { Literacy rate, } \\
\text { aged 15+ (\%) }\end{array}$ \\
\hline Iran & 94 & 94 & 100 & 5.2 & 84 \\
Sri Lanka & 99 & 97 & 97 & 5.4 & 91 \\
Maldives & 100 & 97 & 97 & 8.3 & 97 \\
India & 128 & 89 & 87 & 3.3 & 65 \\
Pakistan & 136 & 66 & 57 & 2.7 & 54 \\
Nepal & 145 & 79 & 74 & 3.2 & 55 \\
Bangladesh & 140 & 89 & 90 & 2.8 & 52 \\
\hline
\end{tabular}

Note: Gross National Product (GNP); Net Enrollment Ratio (NER).

Source: UNESCO (2010). 
presence of women and girls in education projects. At best, special facilities for girls and boys have been a means of demonstrating equality of access. To this effect, $60 \%$ of the funds for the Punjab Education Sector Reforms Program were earmarked for spending on 'missing facilities' for girls' schools in the state (Punjab Women Empowerment Package 2012). As such, the Government of Pakistan has acknowledged its failure in raising the educational levels of the female population significantly, especially those living in rural areas (Ministry of Education 2009). However, its focus has continued to be that of providing facilities rather than addressing the social and cultural impediments.

With this backdrop, we understand the failings to improve female education through the dominant taxonomy of the household unit in Pakistan. It is here that we highlight Pierre Bourdieu's (1992) seminal work The Logic of Practice in how socio-cultural worlds are structured through male and female binaries while also reflecting collective, embodied practices that capitulate to and obey a practical logic shaping the 'habitus'. For our purposes here, the rural household in Punjab reflects a social universe or 'habitus' highlighting this binary, which shapes a two-pronged gendered notion of 'respectability' and honour with, on the one hand, virtues of female domesticity, and on the other, male honour within the public, outward domain. Feminine qualities of nurture centred on the home result in a series of actions and practices that affirm positive associations with female space and the bodily practices associated with it for girls and women. In this sense, girls' schooling represents a direct opposition to the concept of respectability within the rural Punjabi household, by crossing the binaries of male and female and of public and domestic. While Bourdieu's exploration of how inversions of the oppositional binary result in new symbolic functions and meanings within the house as 'The World Reversed', the inversion is asymmetrical for girls and women venturing into the public domain as a risk-invoking act. It is at this nexus of the social world of the rural Punjabi household that the decision-making processes around girls' education takes place in affirming the values associated with the symbolic function of female education, creating a discriminatory objective logic against girls' continuing education.

While we utilise Bourdieu's understandings of the household's objective logic as the moral framework that leads to discrimination against girls to be educated, the most entrenched approach to tackling low levels of female education in Pakistan is human capital theory which draws a correlation between female education and household economic productivity (Colclough 1982). In rural Pakistan, the feudal economy still remains the dominant mode of production, and women's low non-household labour participation and literacy rates show that the human capital theory is thus misplaced. Economic processes are not merely tied to cultural ones but are shaped and constituted by them (Bourdieu 2005). Even in countries where gender parity 
has been obtained in terms of access to basic education, women and girls continue to be excluded from reaping benefits of empowerment and social development associated with education (Chitrakar 2009). In South Asia, gender norms are based around an ideal of the patriarchal extended family in which older, senior men have authority over others, including younger men, and women are 'given away' in marriage. Although women can inherit according to Islamic law, daughters have no claim on their father's patrimony, which is reserved exclusively for sons. Dowries and bride price exchanges between brides' and grooms' families exist outside productive relations such as land or property and therefore do not contribute positively to women's status (Alvi 2007; Agarwal 1994). At best, their success in producing a son places them in a less marginalised position within this system (Purewal 2010).

The impacts that social conventions of seclusion (purdah) and traditional gender roles have upon the autonomy and aspirations of women in Pakistan are ubiquitous, particularly identifiable as girls reach adolescence. This can result in the enforcement of modesty of girls to various degrees, such as the wearing of the veil, withdrawal from school and a socialisation process that veers girls away from the public sphere and towards homeward duties, further reducing their chances of pursuing higher education (Caldwell, Reddy, and Caldwell 1985; Mandelbaum 1988; Shah and Eastmond 1977; Siann and Khalid 1984; Stromquist 1989).

In this light, we draw upon the concepts of returns and 'respectability' that place decision-making around girls' education more appropriately within context for this study. These two approaches, as will be argued, are useful in understanding the objective logic of parental attitudes in rural Pakistan around girls' education. Beyond the remit of returns and respectability lies a complex backdrop of how culture and economics relate to education. Social class is a significant marker of how education is perceived and experienced (Bourdieu and Passeron 1990). For the urban affluent classes of nearby cities such as Faisalabad or Lahore, girls' and women's education are a feature of the social reproduction of privilege (Maskiell 1985). Because the landed affluent classes of most of rural Pakistan tend to live in the cities and extract surpluses from the rural economy, they send their children to schools in urban areas where they can utilise education as a means of bolstering their cultural and social capital. Therefore, those who actually reside in the rural areas of Jhang and Jaranwala are from lower socio-economic groups, for whom girls' education has a different set of considerations less framed by social mobility and more to do with negotiating the economic and social concerns of returns and respectability. In this sense, the cultural capital associated with educational attainment is a luxury reserved for the urban middle and upper classes. With this in consideration, we focus our attention upon the theory of returns and the concept of respectability. 
The theory of returns in which the rationale behind sending children to school and investing in them for later in life is based upon a notion of who will eventually become economically productive contributors to the household. Girls, who are assumed to marry and hence leave their natal homes, are seen as futile investments in this light, while boys are viewed as steadfast investments worthy of a larger share of family resources (Sathar and Lloyd 1994; Sawada and Lokshin 2001; Stith, Gorman, and Choudhury 2003). The notion of men as breadwinners also awards them preferred status over females in terms of their productive potential, which impacts upon how they are invested in early on in life (Dancer and Rammohan 2007; Khan and Ali 2005).

Another perspective views cultural norms that deem girls' vulnerability in the public sphere, including educational opportunities, a matter of 'respectability'. Girls, in this view, maintain and carry the burden of 'respect' or izzat through restrictions on their mobility and circumscribed adherence to social conventions in terms of roles, behaviour, appearance and kinship relations. In this sense, socio-cultural norms of rural society in Pakistan have been acknowledged to have an adverse effect on girls' schooling (Hamid 1993) whereby reservations around 'respectability' come to the forefront of the decision-making equation around sending girls to school. Threats to respectability can stem from walking to school, coming into contact with men unrelated to them, and exposure of girls to ideas not in line with traditional gender roles expected of them.

Parents following the cultural norms that circumscribe the limited mobility options for adult females have been found to place more importance upon girls' modesty than their education as compared with male children (Khan and Ali 2005; Liu 2004; Tansel 2002). The negative association of education for girls is one which views education as a potentially corrupting force on the gender 'balance' of roles within the family, leading girls and women to stray away from traditional gender roles.

The social determinants of girls' education position the cultural context of decision-making alongside economic ones, making respectability an equally important, if not more important, factor as affordability and economic returns (Smits and Hosgor 2006). The expectations of girls to carry the codes of respect through modest behaviour have been found to impact directly upon their potentials for educational attainment and in low expectations from parents and teachers of girls' achievement (Colclough, Rose, and Tembon 2000).

In developing an understanding of decision-making around girls' education, we posit that both 'respectability' and returns contribute to the attitudes of parents. Our examination of the two districts in Pakistani Punjab shows that education is not being perceived as a potential benefit, in part, because of how consanguinity shapes kinship arrangements, which greatly limits the perceived benefits of girls' education as a matter of outward and upward 
mobility. Parental decision-making about ambitions for girls' education, when endogamous in its scope, tends to seek containment of aspiration and mobility, rather than fostering it. The cultural and economic perceptions of girl children and hence the value and risks associated with their education shape the social worlds which shape the decision-making about girls' education. While negative attitudes towards girls' education are a key cause in lowering their access to and attainment of education (Subrahmanian 2005), the comparatively negative attitude towards girls' education compared with boys' education is in need of further examination for both cultural and economic considerations.

\section{The study}

This study is based upon fieldwork conducted in two areas in the Pakistan province of Punjab: Jaranwala town (District Faisalabad) and Tehsil Chiniot (District Jhang). The population of Jaranwala town and Tehsil Chiniot are 917,701 and 705,941 respectively (Government of Pakistan 2000). The province of Punjab, in comparison with other Pakistan provinces, has the second highest total literacy rate, the highest female literacy rate, and the highest gender parity index (Table 3). The two selected districts of Faisalabad and Jhang are respectively medium-ranking and low-ranking in terms of female literacy in comparison with other districts in the province (Table 4).

The quantitative dimension of the study is based on a household survey for which the sample size of 350 was selected through a proportional allocation technique from both of these selected areas. With a view to include a broader sample, five chaks (villages) were selected randomly from each of these two areas. Schools in these areas are mainly government schools, with only a minute presence of privately owned schools in these rural areas. The survey areas varied from 5 to 20 kilometres from urban conurbations. Households comprising children of both sexes of school-going age were selected randomly from each village.

In terms of women's participation in public life, the presence of women in the public sphere is limited, with little evidence of participation in formal political activities. However, this does not mean that women are absent from public life altogether and their presence, largely through the private sphere and its links to more informal family and community networks, is an integral part of rural Punjabi society. Consequently, women were sought out in the survey as it was understood that women play a significant role in the decision-making processes of the family. In these areas, the moral influence of the Ulema could be said to be stronger in lower-class and working-class households with a more significant influence of biraderi (clan) kinship networks and senior family members' authority on a broader societal level. 
Table 3. Literacy rate at 10 years and above and Gender Parity $\operatorname{Index}^{\mathrm{a}}$ by province.

\begin{tabular}{|c|c|c|c|c|}
\hline \multirow{2}{*}{\multicolumn{2}{|c|}{ Region/province }} & \multicolumn{3}{|c|}{ Literacy rate ( 10 years and above) } \\
\hline & & \multirow{2}{*}{$\begin{array}{c}2006 / 07 \\
67\end{array}$} & \multirow{2}{*}{$\begin{array}{c}2007 / 08 \\
69\end{array}$} & \multirow{2}{*}{$\begin{array}{c}2008 / 09 \\
69\end{array}$} \\
\hline Pakistan & Male & & & \\
\hline & Female & 42 & 44 & 45 \\
\hline & Both & 55 & 56 & 57 \\
\hline & GPI & 0.63 & 0.64 & 0.65 \\
\hline \multirow[t]{4}{*}{ Punjab } & Male & 67 & 70 & 69 \\
\hline & Female & 48 & 48 & 50 \\
\hline & Both & 58 & 59 & 59 \\
\hline & GPI & 0.72 & 0.69 & 0.72 \\
\hline \multirow[t]{4}{*}{ Sindh } & Male & 67 & 69 & 71 \\
\hline & Female & 42 & 42 & 45 \\
\hline & Both & 55 & 56 & 59 \\
\hline & GPI & 0.63 & 0.61 & 0.63 \\
\hline \multirow{4}{*}{$\begin{array}{l}\text { Khyber } \\
\text { Pakhtunkhwa }\end{array}$} & Male & 67 & 68 & 69 \\
\hline & Female & 28 & 33 & 31 \\
\hline & Both & 47 & 49 & 50 \\
\hline & GPI & 0.42 & 0.49 & 0.45 \\
\hline \multirow{4}{*}{ Balochistan } & Male & 58 & 66 & 62 \\
\hline & Female & 22 & 23 & 23 \\
\hline & Both & 42 & 46 & 45 \\
\hline & GPI & 0.38 & 0.35 & 0.37 \\
\hline
\end{tabular}

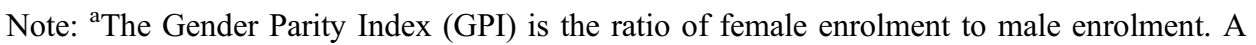
GPI of one means that for every male at school there is one female.

Source: Pakistan Social \& Living Standard Measurement Survey 2008/09.

The survey and interviews were conducted by both male and female Pakistani social science postgraduate students at Government College Faisalabad. Faisalabad is the largest city in the area, being second in size only to Lahore in the state, and thus most of the research assistants originated from the two districts of Jhang and Jaranwala that were the focus of the study. There was a significant level of cultural and linguistic familiarity of the research assistants and the authors with the locality. Thus, the questions being asked in the questionnaire and semi-structured interviews with respect to attitudes towards education resonated on both epistemological and ontological levels. The survey data were input by the research students, and the interviews were conducted and transcribed in Punjabi by the research assistants and then translated by the authors. The survey questions were first piloted in order to establish clarity in how participants would perceive the questions. The study's starting point, drawn from quantitative indicators showing comparatively low enrolment and literacy rates of girls compared with boys (Tables 3 and 4), is that there is bias against girls' education. However, when the original thematic questions were administered through 
Table 4. Literacy rate in selected districts in the Pakistan province of Punjab.

\begin{tabular}{lcccr}
\hline & \multicolumn{2}{c}{ Total } & \multicolumn{2}{c}{ Gender disaggregated } \\
\cline { 2 - 3 } \cline { 5 - 5 } District & 1981 & $1998^{\mathrm{a}}$ & Male & Female \\
\hline All Punjab & 27.4 & 46.6 & 57.2 & 35.1 \\
Bahawalpur & 20.4 & 35.0 & 44.9 & 24.0 \\
D.G. Khan & 16.3 & 30.6 & 42.1 & 18.1 \\
Faisalabad & 31.8 & 51.9 & 60.9 & 42.2 \\
Jhang & 20.3 & 37.1 & 51.5 & 21.4 \\
Toba Tek Singh & 30.3 & 50.5 & 61.3 & 39.1 \\
Gujranwala & 29.9 & 56.6 & 63.6 & 48.8 \\
Gujrat & 31.3 & 62.2 & 73.0 & 51.6 \\
Narowal & 25.5 & 52.7 & 65.6 & 39.8 \\
Sialkot & 30.8 & 58.9 & 65.9 & 51.5 \\
Lahore & 48.4 & 64.7 & 69.1 & 59.7 \\
Kasur & 18.7 & 36.2 & 47.6 & 23.4 \\
Nankana & & (Included in & Sheikhupura District) & \\
Okara & 24.8 & 37.8 & 49.3 & 25.0 \\
Sheikhupura & 22.4 & 43.8 & 53.3 & 33.3 \\
Multan & 23.5 & 43.4 & 53.3 & 32.3 \\
Pakpattan & 16.9 & 34.7 & 47.0 & 21.3 \\
Sahiwal & 21.7 & 43.9 & 54.7 & 32.3 \\
Rawalpindi & 46.6 & 70.4 & 81.2 & 59.2 \\
Attock & 21.1 & 49.3 & 66.9 & 32.0 \\
Chakwal & 39.7 & 56.7 & 73.4 & 42.2 \\
Jhelum & 38.9 & 68.9 & 77.0 & 50.5 \\
Sargodha & 24.9 & 46.3 & 59.2 & 32.7 \\
Mianwali & 21.4 & 42.8 & 63.8 & 22.1 \\
\hline Not: & & & & \\
\hline
\end{tabular}

Note: ${ }^{a}$ Census of Pakistan 1998, Population Census Organization, Government of Pakistan. The most recent census in Pakistan was conducted in 1998.

the pilot questionnaire, it was found that less direct questions around children's education did not elicit cogent responses. Thus, the questions were refined to be more explicitly focused upon the notion of gender bias, rather than being circumspectly posed around general attitudes towards girls' education. For this reason, leading questions were framed as a means of not only drawing out opinions and attitudes for the survey but also to identify cases for the qualitative interviews. While the strong wording of the leading questions around 'bad practices' and 'rebellion' is a limitation in that they are provocative in reflecting culturally dominant ideas about gender, this also had benefits to the study in that disagreement and contestation with this stereotype were also elicited. The methodological outcome of stating leading questions was that the results produced a focused engagement of the sample with the social context of gender discrimination and bias at the household level. The study was able to penetrate the surface of parental decision-making and make a number of findings around how overt and residual bias are expressed in perceptions of girls' education by parents. Twelve 
semi-structured qualitative interviews were conducted with cases identified in the survey exhibiting significant engagement with the key leading questions. Gender dynamics of power in the interview process were reflected upon in the notes taken by the research assistants in the ways in which the head of household $(\mathrm{HOH})$, if a man was present, would be de facto identified as the male head of household. This was addressed through a concerted effort to employ a system of 'positive discrimination' to ensure as much of a balance as possible of female voices within the qualitative and quantitative data collection.

\section{Dependent variables}

Negative attitudes towards female education are a root cause of low educational levels of girls in rural Pakistan. Parents' attitudes towards their daughters' schooling were measured through three main questions: Question I, 'Whose schooling is more necessary - girls/boys/both?'; Question II, 'Does higher level education cause girls to become rebellious against parents?' (on a Likert scale); and Question III, 'Do parents believe girls are likely to indulge in "bad practices" by attending higher level schooling?' (on a Likert scale). The notion of 'bad practices' for girls means the stigma associated with girls having mobility within the public sphere and the potential risks this may present to their 'respectability'. Thus, education could be seen as having a corrupting influence upon girls. This might include concerns around girls' demands to choose their life partner or options to have romantic or sexual relations with males outside the bounds of normative, parentally-endorsed marriage. In Pakistan, sexual relations out of marriage are subject to prosecution under the Zina Hodood Ordinance; and a woman found guilty is deemed unlawful, disreputable and unacceptable within the normative bounds of society, making it difficult for her parents to find a life partner for her. Indeed, 'honour killings' encapsulate the most extreme reaction to this notion of 'bad practices' in which women have even been killed by male family members to uphold their families' respect. This burden of respectability that girls carry will be further explored as a key factor in parents' decisions about their schooling. Throughout the discussion and analysis of findings, these three questions will be referred to as Question I, Question II and Question III.

\section{Heads of households - patriarchal authority and decision-making around girls' education}

Male HOHs emerged as an overrepresented group within the sample. Despite mothers' and women's representation being an explicit priority from the onset of the data collection stages of the research, only $45 \%$ of the 350 sample investigations were conducted with women due to limited access to 
females through the household survey method and a notable pattern of insistence at the time of interview that male $\mathrm{HOHs}$ act as the respondents due to formal authority. However, even in most cases where the male $\mathrm{HOH}$ was the main respondent, women were generally also present and participated in the questionnaire. While this is a limitation in terms of ascertaining the power dynamics, the qualitative interviews provide a certain amount of recourse to fill in some of the gaps created by this. Schooling outcomes for girls have been argued to be affected by the perceptions and social characteristics of the HOHs (Mare 1980) and, in particular, about girls' higher level schooling (Chernichovsky 1985; Dancer and Rammohan 2007; Khan and Ali 2005; Sawada and Lokshin, 2001). Similarly, Buchmann and Hannum (2001) inferred that in developing countries the education of rural girls face the vicious cycle of poor cultural beliefs of the male HOHs. These beliefs promote the idea that higher level education is not suitable for girls (Stith, Gorman, and Choudhury 2003). Parish and Willis (1993) go further in arguing that patriarchy causes parents to manipulate their girls in the benefit of their boys. We would argue that the threat of 'rebellion' posed by education and its accompanying access to the public sphere serves as a justification for the dominant hegemony of the household. It is here that objective logic formulates parents' attitudes to at best be tacitly supportive of girls to attend school and at worst be negative about education's potentially corrupting influences on their daughters.

\section{Results}

\section{Question I: gender-biased attitude}

Question I poses a choice between preference for girls' or boys' education or showing no bias. More than one-half of the HOHs (52\%) were found to be in favour of boys' schooling as compared with that of girls'. The percentage of those identifying themselves in favour of girls' schooling over boys was merely $1.7 \%$, yet those showing no bias when asked whose education they preferred - girls' or boys' - constituted a significant $46.3 \%$ (Table 5). This latter figure of un-bias in part reflects a public discourse (brought out by the questionnaire method) that defends education generally and that of both daughters' and sons', showing that there are more complex contours of gender-biased attitudes (GBAs) beneath such starkly posed questions, which we follow up in Questions II and III. What Question I does highlight, however, is that there is a sizeable proportion of parents overtly stating that they have no bias against girls' education (46.3\%) alongside another sizeable proportion of parents who prefer boys' education to girls' $(52 \%)$, which points to a vast cultural terrain comprised of the objective logic discussed earlier. We break this down into a scenario of both overt gender bias and a residual gender bias. Residual bias may not be apparent under Question I, which frames a 'boys versus girls' choice. The 
Table 5. Attitude of fathers towards girls' schooling.

\begin{tabular}{lc}
\hline & Total, count $(\%)$ \\
\hline Question I: gender-biased attitude & \\
Biased towards girls & $6(1.7)$ \\
Unbiased & $162(46.3)$ \\
Biased towards boys & $182(52.0)$ \\
Test statistic: Somer's $D, p<0.0001$ & \\
Question II: schooling causes girls to be & \\
rebellious towards parents & \\
Strongly agree & $97(27.7)$ \\
Agree & $86(24.6)$ \\
No opinion & $7(2.0)$ \\
Disagree & $121(34.6)$ \\
Strongly disagree & $39(11.1)$ \\
Test statistic: Somer's $D, p<0.0001$ & \\
Question II: schooling encourages 'bad practices' & \\
among girls & \\
Strongly agree & $80(22.8)$ \\
Agree & $92(26.3)$ \\
No opinion & $17(4.9)$ \\
Disagree & $121(34.6)$ \\
Strongly disagree & $40(11.4)$ \\
Test statistic: Somer's $D, p<0.0001$ & \\
Total, count (\%) & $350(100)$ \\
\hline
\end{tabular}

same parents who state they are unbiased may also reflect strong concerns about respectability and returns, as will be discussed in relation to Questions II and III, showing the limits of the statistical indicators of GBA.

The qualitative interviews highlight a number of tensions existing within these overt and residual expressions of gender bias that place value judgements on perceived economic returns and potential threats to respectability surrounding children's education. The notion that sons' education represents an economic investment accompanies the sense that girls' education is not perceived as a productive activity with benefits or returns, and instead detracts from the emphasis upon women's work within the home. One male $\mathrm{HOH}$ respondent justified the rationale for bias against girls' education:

We have to prefer sons' education over daughters' education. Educated sons help fathers to meet the household expenditures, so they should get education to become an officer, whereas, daughters should help their mothers. Mothers have to do household chores, so daughters do not really need higher education. (Male 38, age 53)

The futility of investing in the education of daughters who are viewed as temporary investments and thus provide low economic return is another aspect of gender bias also commented upon: 
Table 6. Attitude of mothers towards girls' schooling.

\begin{tabular}{lc}
\hline & Total, count (\%) \\
\hline Question I: gender-biased attitude & \\
Biased towards girls & $6(1.7)$ \\
Unbiased & $162(46.3)$ \\
Biased towards boys & $182(52.0)$ \\
Test statistic: Somer's $D, p<0.0001$ & \\
Question II: schooling causes girls to be rebellious towards & \\
parents & \\
Strongly agree & $97(27.7)$ \\
Agree & $86(24.6)$ \\
No opinion & $7(2.0)$ \\
Disagree & $121(34.6)$ \\
Strongly disagree & $39(11.1)$ \\
Test statistic: Somer's $D, p<0.0001$ & \\
Question III: schooling encourages 'bad practices' among girls & \\
Strongly agree & $80(22.8)$ \\
Agree & $92(26.3)$ \\
No opinion & $17(4.9)$ \\
Disagree & $121(34.6)$ \\
Strongly disagree & $40(11.4)$ \\
Test statistic: Somer's $D, p<0.0001$ & \\
Total, count (\%) & $350(100)$ \\
\hline
\end{tabular}

Our son would be head of the household. He has to earn and feed the family, whereas daughters are paraaya dhaan [transl. 'the wealth of others'] and have to eventually move to another home; why should we educate them? We will educate our sons and get them recruited in the Police or Army ... we will train her (daughter) for household chores and then marry her off. (Female housewife 19)

The widely accepted convention of girls' imminent marriage resulting in their departure from their natal homes was a commonly cited explanation for the bias against girls' education. The value attached to girls' education is thus closely associated with the prominent emphasis upon marriage for women's life prospects in rural Pakistani society, often with women themselves asserting this upon their daughters' prospects for education (Table 6).

The spatial and security dimensions of girls travelling to and from school and sensibilities in maintaining girls' 'respectability' in the public sphere provides another set of rationale for gender bias against girls' schooling:

$\ldots$ girls in our society are not allowed to wander outside the home. Therefore, we are not willing to send them to cities for education. (Male 38, age 53)

Thus, the results on GBA show a presence of overt bias accompanied by a residual bias when combined with the analysis of Questions II and III, 
which shows pressures to succumb to societal curbing of girls' mobility in turn forcing parents to weigh up both benefits and risks associated with sending girls to school. In essence, as girls get older and reach higher levels of education even within the primary/elementary stage, the risks and benefits become increasingly skewed against their continuing education. However, this shows a more complex picture of GBA than Question I is able to illuminate.

\section{Question II: social control and girls' compliance}

The analysis of Questions II and III highlights dynamics of both overt and residual bias against girls' education. When the entire sample (including both cohorts of $52 \%$ biased towards boys' education and $46.3 \%$ unbiased from Question I) were asked about perceptions of girls' education specifically, the residual considerations come to the fore. What emerges is a picture of variation and contestation, although this is still framed within the objective logic that deems girls' mobility, and thus education, a site of debate.

Structural and cultural dimensions of the limits placed upon women's mobility also have more subliminal, internalised dimensions reflected in social norms when it comes to girls' education. More than one-half of the HOHs (52.3\%) agreed to the statement that higher education causes girls to become 'rebellious', while those who disagreed constituted 45.7\% (Table 5). This result is mixed and by no means shows an outright rejection of education. However, perhaps more importantly it reveals the complexities underlying parental attitudes that, on the one hand, must consider the benefits of educating their daughters and, on the other, negotiate cultural codes that shape the gendered social fabric of rural social relations. The compliance of girls to norms of social acceptability assumes a status quo in which girls forfeit opportunities for individual advancement for the sake of family desires and codes of honour and reputation.

The notion of rebelliousness stems primarily from fear of transgressions from the norms of marriage, which are by and large arranged within biraderi family networks. Education in this sense must be viewed within this context in how it relates to social relations that rely upon compliance by both males and females. Girls' education is thus a considerable factor in ensuring that this compliance is maintained, as marriage is central to the social fabric of rural society in Pakistan.

In our rural society, sons are our heirs. Fathers avoid higher level schooling of daughters as highly educated girls make demands for inheritance and start behaving like brothers in demanding the same status ... Parents experience difficulties for marrying highly educated daughters, as within family (marriage within kin group) highly educated matches are rare. (Male 21) 
Thus, girls' education from the perspective of social control and compliance appears, as by this respondent, to be a liability rather than a benefit to the family. Elements of social conservatism present fears to parents of girls becoming too educated and disrupting conventions around inheritance and kinship relations, and in this sense becoming 'rebellious'.

\section{Question III: respectability}

When presented with the statement that education causes 'bad practices', more than one-fifth of fathers (22.9\%) 'strongly agreed' while $49.1 \%$ 'agreed' with this statement (Table 5). However, $46 \%$ of the fathers did not support the statement. Thus, what can be said is that the high ratio of fathers with generally negative perceptions about female education on Question I and Question II highlights the challenges that social conservatism plays through the will and attitudes of the HOHs to maintain certain 'balances' of culture and the family through gender.

Girls being visible within the public sphere during travel to and from school and in mixed-gender schools were other causes of apprehension acting as deterrents for parents in sending their daughters to school. As one teacher commented:

The cultural environment of rural areas is such that they like to educate girls just to literacy levels so that they can read and write. The reason is that highly educated girls may want to have a 'love marriage' (a marriage out of their own choice and accord) through their interactions in the coeducational system at college or university ... and parents lose their honour. (Male teacher 9)

The fear of losing control of daughters' whereabouts and interactions lies at the heart of many parents' apprehensions. One mother commented strongly against sending girls to school outside the immediate vicinity of the village:

By educating daughters, the family's respect can be destroyed. When they will be away from home, they will act according to their will. Who is watching over them then? These older girls should be kept at home. We [parents] should be aware of whether a daughter is standing or sitting. (Female 5, Age 39)

\section{Conclusion}

This study has focused upon parental attitudes towards their daughters' education. At the onset, we situated the two concepts - returns and 'respectability' - within Bourdieu's (1992) objective logic in terms of what shapes the social worlds of gender in terms of attitudes to girls' education in rural Pakistan. The two themes of returns and 'respectability' emerged as key 
concerns that parents from the selected districts of rural Pakistan revealed about their daughters' education, and in this sense represent the dominant taxonomy of the household in which decisions are made around children's education. At the onset, we argued that girls' education immediately poses a challenge to the binaries of male and female spaces so central to the social world of the rural Punjabi household by drawing girls out of the feminine, inward space to the outward, masculine public space. The continuing failure of policies to bring about significant improvements in female education is due to an inability to recognise this fundamental feature.

Boys' educational attainment, while still being a matter of family status and respect, is perceived as positive for the family unit that positions boys' prospects at an advantage compared with girls'. Girls' educational prospects, on the other hand, are subject to scrutiny by parents uneasy about both the returns for sending their daughters to school and the perceived risks associated with girls' mobility in the public sphere, particularly beyond the age of 10 .

An underlying dimension of GBA in rural Pakistan is the negative connotation of girls' education. Parental attitudes to girls' education are laden with a rationale about girls' vulnerable and potentially corruptible position within society that goes beyond a simplistic understanding of fundamentalist Islam and gender, as media analysis of the case of Malala Yousafzai has crudely indicated. The variations that exist within our sample highlight the juncture between bias as an oppositional stance to girls' education and bias as a set of concerns that generate tension, complexity and variation. Reluctance to put one's own daughter and family in a position of vulnerability remains a significant factor in parental decision-making. However, as we have argued, this is part of a broader objective logic formulated by a matrix of economic, social and cultural factors that not even Taliban interests can claim to represent.

Both the quantitative and qualitative dimensions of this study highlighted a prominent understanding of girls' circumscribed position within the family. It is therefore not surprising that the introduction of free universal education in Pakistan in 2004 has not shown immediate impacts upon girls' education. With such underlying dimensions to parental decision-making around their children's education at the household and grassroots level, the task of encouraging parents to send their daughters to school entails addressing cultural and social norms as they relate to the broader processes and institutions of education. The preoccupation with 'rebelliousness' and 'bad practices' that education evokes for rural society in Pakistan exhibits the obstacles to overcoming gender disparity in enrolment, attainment, and literacy when girls' education is societally viewed with suspicion. Thus, both overt and residual bias, as highlighted in this study, need to be addressed. 
Conceptions of educated girls and women by rural society often associate higher schooling with rebelliousness and indecency, as the findings here have shown. This perception of girls' education needs to be tackled alongside the wider promotion of girls' education by non-governmental organisations, the Ministry of Education and other government and international agencies as a means of addressing the gender-biased attitude, both overt and residual, which is rampant in rural Pakistan. Implicit in the shortcomings of policy approaches towards girls' education is an ineffective and often inappropriate understanding of how gender roles, expectations and values around education relate to the wider social sphere (Aikman and Unterhalter 2005). Only then can there be a chance of improving gender disparities within education.

\section{Acknowledgements}

The research for this article was enabled by a grant from the Commonwealth Scholarship Commission [PKCF-2011-183] through which Naimatullah Hashmi was awarded a post-doctoral fellowship to the University of Manchester 2011/12. The authors are grateful to the Commonwealth Scholarship Commission for supporting this research, to the social science postgraduate students at Government College University Faisalabad in Pakistan for assisting in the data collection for the study, and to the three anonymous reviewers for their invaluable comments.

\section{References}

Aikman, S., and E. Unterhalter. 2005. Beyond Access: Transforming Policy and Practice for Gender Equality in Education. London: Oxfam Publications.

Agarwal, B. 1994. A Field of One's Own: Gender and Land Rights in South Asia. Cambridge: Cambridge University Press.

Alvi, Anjum. 2007. "India and the Muslim Punjab: A Unified Approach to South Asian Kinship," Journal of the Royal Anthropological Institute.

Asian Development Bank. 2008. Education and Skills: Strategies for Accelerated Development in Asia and the Pacific, June 2008, 82.

Bourdieu, P. 2005. The Social Structures of the Economy. Cambridge: Translated by Chris Turner, Polity.

Bourdieu, P., and J. C. Passeron. 1990. Reproduction in Education, Society and Culture. London: Sage.

Bourdieu, P. 1992. The Logic of Practice. Cambridge: Polity Press.

Buchmann, C., and E. Hannum. 2001. "Education and Stratification in Developing Countries: A Review of Theories and Research." Annual Review of Sociology 27: 77-102.

Caldwell, J., P. Reddy, and P. Caldwell. 1985. "Educational Transition in Rural South India." Population and Development Review 11 (1).

Chernichovsky, D. 1985. "Socioeconomic and Demographic Aspects of School Enrollment and Attendance in Rural Botswana." Economic Development and Cultural Change 33 (2): 319-332.

Chitrakar, R. 2009. Overcoming Barriers to Girls' Education in South Asia: Deepending the Analysis. UNICEF Regional Office for South Asia: Kathmandu. 
Colclough, C. 1982. "The Impact of Primary Schooling on Economic Development: A Review of the Evidence." World Development 10 (3): 167-185.

Colclough, C., P. Rose, and M. Tembon. 2000. "Gender Inequalities in Primary Schooling: The Roles of Poverty and Adverse Cultural Practice." International Journal of Educational Development 20: 5-27.

Dancer, D., and A. Rammohan. 2007. "Determinants of Schooling in Egypt: The Role of Gender and Rural/Urban Residence." Oxford Development Studies 35 (2): 171-195.

DFID (Department For International Development). 2005. “Girls' Education: Towards a Better Future for All". UK Government.

Government of Pakistan. 2000. Population Census-1998. Population Census Organisation, Statistics Division, Govt. of Pakistan, Islamabad

Government of the Punjab. 2012. Punjab Women Empowerment Package 2012. Women Development Department, Lahore: Pakistan.

Hamid, S. 1993. "A Micro Analysis of Demand-Side Determinants of Schooling in Urban Pakistan." The Pakistan Development Review-Part II 32 (4): 713-723.

Khan, R. E. A. and K. Ali. 2005. "Bargaining over Sons and Daughters' Schooling: Probit Analysis of Household Behaviour in Pakistan." Working Paper 01-05, Department of Economics, Islamia University Bahawalpur, Pakistan.

Liu, A. Y. C. 2004. "Flying Ducks? Girls' Schooling in Rural Vietnam - A Revisit." International and Development Economics, National Centre for Development Studies, Asian Pacific School of Economics and Government, Australian National University Canberra, ACT 0200, Australia.

Mandelbaum, D. 1988. Women's Seclusion and Men's Honor: Sex Roles in North India, Bangladesh and Pakistan. Tucson, AZ: University of Arizona Press.

Mare, R. D. 1980. "Social Background and School Continuation Decisions." Journal of the American Statistical Association 75 (370): 295-305.

Maskiell, M. 1985. "Social Change and Social Control: College-Educated Punjabi Women 1913-1960.” Modern Asian Studies. 19 (1): 55-83.

Minh-ha, T. 1989. Woman, Native. Bloomington: Other. Writing Postcoloniality and Feminism. Indiana University Press.

Ministry of Education. 2009. NEP (National Education Policy). Islamabad: Government of Pakistan.

Mohanty, C. A. 1991. "Under Western Eyes: Feminist Scholarship and Colonial Discourses." In Third World Women and the Politics of Feminism, edited by C. A. Mohanty, A. Russo, and L. Torres, 51-80. Bloomington: Indiana University Press.

National Population Policy. 2010. Ministry of Population Welfare. Pakistan: Islamabad.

Parish, W. L., and R. J. Willis. 1993. "Daughters, Education, and Family Budgets Taiwan Experiences." The Journal of Human Resources 28 (4): 863-898.

Purewal, N. 2010. Son Preference: Sex Selection, Gender and Culture in South Asia. Oxford: Berg.

Qureshi, S. 2004. Pakistan: Education and Gender Policy, Girl's Education: A Lifeline to Development. Budapest, Hungary: Center For Policy Studies.

Saha, R. 2005. The Determinants of the Changing Educational Gender Gap in Brazil. Department of Economics, Ithaca, New York: Cornell University.

Sathar, Z. A., and C. B. Lloyd. 1994. "Who Gets Primary Education in Pakistan? Inequalities among and within Families." The Pakistan Development Review 30 (2): 103-134. 
Sawada, Y. and M. Lokshin. 2001. "Household Schooling Decisions in Rural Pakistan.” Policy Working Research Paper 2541. Poverty and Human Resources Development Research group, World Bank, Washington D.C.

SDPI (Sustainable Development Policy Institute). 2008. Pakistan: Country Gender Profile. Final Report 2007-2008. Islamabad. http://www.jica.go.jp/pakistan/ english/office/others/pdf/CGP_01.pdf

Shah, S., and J. Eastmond. 19777. Primary Education in the Rural Villages of Pakistan, 1976-77. Islamabad: Ministry of Education.

Siann, G., and R. Khalid. 1984. "Muslim Traditions and Attitudes to Female Education." Journal of Adolescence 7: 191-200.

Smits, J., and A. G. Hosgor. 2006. "Effects of Family Background Characteristics on Educational Participation in Turkey." International Journal of Educational Development 26: 545-560.

Social Indicators of Pakistan. 2011. Statistics Division. Islamabad: Government of Pakistan.

Song, L., S. Appleton, and J. Knight. 2006. "Why Do Girls in Rural China Have Lower School Enrolment?” World Development 34 (9): 1639-1653.

Stith, A. Y., K. S. Gorman, and N. Choudhury. 2003. "The Effects of Psychosocial Risk and Gender on School Attainment in Guatemala." Applied Psychology: An International Review 52 (4): 614-629.

Stromquist, N. P. 1989. "Determinants of Educational Participation and Achievement of Women in the Third World: A Review of the Evidence and a Theoretical Critique." Review of Educational Research 59 (2): 143-183.

Subrahmanian, R. 2005. "Gender Equality in Education: Definitions and Measurements." International Journal of Educational Development 25: 395-407.

Suleri, S. 1992. "Woman Skin Deep: Feminism and the Postcolonial Condition." Critical Enquiry, Summer 1992: 756-769.

Tansel, A. 2002. "Determinants of School Attainment of Boys and Girls in Turkey: Individual, Household and Community Factors." Economics of Education Review 21: 455-470.

UNESCO. 2010. Why Gender Equality in Basic Education in Pakistan? Islamabad: Pakistan.

UNFPA. 2009. Holding up the Sky: Women, Population and Climate Change, UNFPA, State of World Population-2009. Pakistan Supplement: University of Gujrat, Pakistan.

UNICEF. 2006. Education for All. http://www.unicef.org/education/index 44870.html

World Economic Forum. 2013. The Global Gender Gap. http://www3.weforum.org/ docs/WEF_GenderGap_Report_2013.pdf. Downloaded 26 October 2013. 